\title{
MEDIÇÃO DE ENERGIA NO ENSAIO SPT EM SOLO TROPICAL DO CAMPO EXPERIMENTAL DA EECA/UFG - GOIÂNIA
}

\section{SPT energy measurement on tropical soil from experimental area of EECA/Federal University of Goiás - Goiânia}

\author{
Humberto Carlos de Oliveira Jardim ${ }^{1}$, Romulo Rodrigues Machado ${ }^{2}$, Pedro Augusto Machado Jorge ${ }^{3}$, \\ Renato Resende Angelim ${ }^{4}$, Renato Cabral Guimarães ${ }^{5}$
}

Recebido em 17 de julho de 2017; aceito em 17 de outubro de 2017; disponível on-line em 09 de março de 2018.

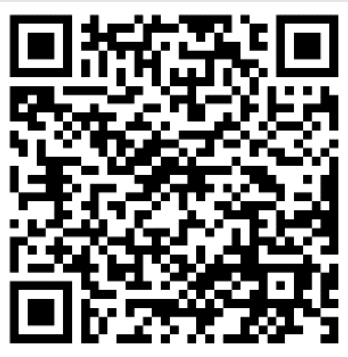

ARTIGO EM REVISÃO

EM BREVE VERSÃO FINAL

PALAVRAS CHAVE:

Ensaios de campo;

Sondagem;

Investigação Geotécnica;

SPT;

Medição de Energia;

\section{KEYWORDS:}

Site investigations;

In-situ tests;

Geotechnical

Investigation;

SPT;

Measurement of energy;

RESUMO: O Standard Penetration Test (SPT), ensaio de campo mais utilizado no Brasil, embora normalizado, pode apresentar grande variação de resultados devido aos diferentes procedimentos e equipamentos utilizados. A medição da energia transmitida às hastes durante a realização do ensaio surge como alternativa de agregar valor ao ensaio possibilitando a melhor comparação entre resultados de ensaios realizados por equipes e equipamentos diferentes. Este trabalho tem o objetivo de comparar medições de energia do ensaio SPT realizadas no solo tropical do campo experimental da Escola de Engenharia Civil e Ambiental da Universidade Federal de Goiás em Goiânia, para difundir esta técnica, formar um banco de dados e demonstrar os benefícios de sua utilização. Para se realizar a análise teórico-experimental foram utilizados acelerômetros e medidores de deformação em haste instrumentada, por meio de um analisador de ondas dinâmicas, que permitiu o monitoramento em tempo real de cada golpe do martelo e posterior transferência de dados para software de análise computacional. A principal contribuição do trabalho foi validar a importância de se utilizar o correto intervalo de integração para análise dos dados e que a energia transmitida ao topo da composição de hastes independeu do comprimento destas e da resistência do solo para as condições deste estudo. Além destas avaliações esse trabalho contribui também para construção de banco de dados de SPT com medição de energia para equipes e equipamentos locais.

ABSTRACT: The Standard Penetration Test (SPT), widely used in Brazil, although normalized, may present significant variations on the results caused by the different equipment and procedures used. The measurement of the kinetic energy arriving to the rod during the test is an alternative to improve the valor of the test, making possible to compare the results obtained by different equipment and teams. This study has the objective to compare different energy evaluations of the SPT on tropical soils in the experimental field of the Civil Engineering School from the Federal University of Goiás in Goiania, to disseminate this technique, build a database and demonstrate the advantages of its use. For the theoretical-experimental analysis, it was used accelerometers and strain gauges on an instrumented rod using a dynamic wave analyzer which allowed the simultaneous monitoring of each hit and posterior analysis of this data on software for this purpose. The main contribution of this research is to validate the importance of choosing the correct integration interval for the analysis of the data of the kinetic energy transferred to the anvil and that this energy is not affected by the length of the rod nor by the soil resistance under this research conditions. Also, it expects to contribute on a database of the energy measured SPT for local teams and equipment.

\footnotetext{
* Contato com os autores:
}

${ }^{1}$ e-mail: humberto.carlosoj@gmail.com (H. C. O. Jardim)

Graduando em Eng. Civil, Universidade Federal de Goiás.

2e-mail: romulorodrimachado@gmail.com (R. R. Machado)

Graduando em Eng. Civil, Universidade Federal de Goiás.

${ }^{3}$ e-mail: pedroaugustomsj@hotmail.com (P. A. M. Jorge)

Graduando em Eng. Civil, Universidade Federal de Goiás.

${ }^{4}$ e-mail: tecnoeng@gmail.com (R. R. Angelim)

Eng. Civil, Doutor, Prof. do Prog. de Pós-graduação Geotecnia, Estrutura e Construção Civil (GECON) da Escola de Engenharia Civil e

Ambiental (EECA) da UFG.

${ }^{5}$ e-mail: renato.guimaraes@ueg.br (R.C. Guimarães)

Eng. Civil, Dr., Prof. do Curso de Eng. Civil da Universidade Estadual de Goiás (UEG) e Eng. de Eletrobrás-Furnas. 


\section{INTRODUÇÃO}

O Standard Penetration Test (SPT) é um dos ensaios geotécnicos de campo mais difundidos no mundo e o mais utilizado no Brasil devido à sua praticidade de execução, à sua aceitação pela classe geotécnica e ao seu baixo custo operacional (DÉCOURT et al., 1988). Até os anos de 1970 existia, porém, a impossibilidade de se comparar os resultados obtidos devido aos diferentes ajustes e equipamentos utilizados. Desde então, buscaramse formas de medir a energia que é transmitida ao conjunto de tubos de cravação até o amostrador que penetra o solo. As pesquisas desenvolvidas por Kovacs et al. (1977), Palacios (1977), Schmertamann e Palacios (1979) e Belincanta (1985) são consideradas marcos para a medição de energia no ensaio SPT, pois foram os principais pesquisadores a desenvolverem estudos relacionados a esse tema. Na sequência outros pesquisadores, como por exemplo, Drumright (1996), Abou-Matar e Goble (1997), Cavalcante (2002) e Odebrecht (2003) desenvolveram estudos com enfoque na medição de energia do ensaio SPT.

Mesmo com diversos estudos realizados sobre a medição de energia no ensaio SPT este procedimento não foi incorporado à rotina do ensaio brasileiro. Esse fato ocorre, provavelmente, devido aos custos iniciais do investimento na compra e na importação do equipamento, à diminuição da produtividade do ensaio, à necessidade de mão de obra especializada para operação do equipamento, à dificuldade em repassar os custos ao preço final da sondagem e à falta de exigência por parte dos projetistas.

Ainda no que diz respeito ao ensaio SPT, embora a normalização padronize os equipamentos e os procedimentos do ensaio, é comum encontrar diferentes tipos de equipamentos sendo utilizados. É ainda mais comum constatar alterações e adaptações nos procedimentos realizados em campo pelos operadores do ensaio no sentido de melhorar a produtividade do processo.

Dessa forma, acredita-se que a medição da energia do ensaio SPT em solo tropical, na cidade de Goiânia, para realização do presente trabalho, contribui para a formação de um banco de dados a partir dos resultados locais, determinando o nível de eficiência da energia transmitida ao amostrador padrão para ensaios realizados por empresa local de sondagem, bem como evidencia a influência positiva da medição de energia, no que tange a análise dos resultados dos ensaios SPT por diferentes métodos teóricos que avaliam a eficiência de energia do ensaio.

\section{OBJETIVO}

O objetivo do trabalho é analisar dois furos de sondagem SPT com medição de energia em um perfil de solo tropical do campo experimental na área da Escola de Engenharia Civil e Ambiental (EECA) da Universidade Federal de Goiás (UFG), na cidade de Goiânia, com o intuito de praticar e de difundir a utilização da medição de energia no ensaio SPT, para assim formar um banco de dados local. São ainda objetivos específicos deste trabalho comparar os resultados de energia pelos métodos EFV e EF2 e verificar a validade do método proposto por Odebrecht (2003) para os referidos ensaios e avaliar a influência do comprimento de hastes.

\section{REVISÃO BIBLIOGRÁFICA}

Durante a década de 1970, foram realizados diversos trabalhos com base científica para avaliação dos fatores que poderiam interferir nos resultados do ensaio SPT. Sendo assim, a busca pela medição de energia e eficiência do ensaio entrou em destaque junto à comunidade científica da época. A partir desse momento, se iniciou uma série de estudos sobre a transferência de energia do martelo para as hastes e dissipação de energia durante a realização do SPT (BELINCANTA et al., 1994).

Percebeu-se então uma grande variabilidade nos resultados encontrados (energias e eficiência de energia). Essa constatação deveu-se basicamente a dois fatores: as diferenças dentre os 
vários tipos de equipamentos SPT utilizados no mundo e os métodos empregados para realizar a medição de energia. Quanto aos métodos, existem basicamente dois pelos quais pode-se calcular a energia transferida às hastes, o método EFV e o método EF2. A escolha do método a ser utilizado depende dos equipamentos e da instrumentação disponíveis para realização da medição (CAVALCANTE, 2002; SJOBLOM; BISCHOFF; COX, 2002).

A determinação da energia no ensaio SPT tem como base a Teoria da Equação da Onda. Essa teoria afirma que uma onda de tensão que circula pelas hastes do ensaio SPT é formada por uma parcela de deformação elástica do material e a outra parcela referente à energia cinética (devido ao movimento das partículas) (BELINCANTA e FERRAZ, 2000). A Teoria da Equação da Onda prova que a onda de compressão inicial gerada pelo contato do martelo com as hastes do ensaio SPT é transferida para o amostrador e logo após retorna ao topo da composição de hastes como onda de tração. Essa onda de tração chega a interface entre martelo e hastes no tempo $2 \ell / c$, tempo até o qual existe proporcionalidade entre a força e a velocidade do processo. Nesse momento há uma predominância da onda de tração, que faz com que a haste seja tracionada, se separando do martelo e gerando outro impacto, repetindo o ciclo, até que não haja mais energia disponível no sistema. (MORAIS, 2014).

A teoria sugere ainda que a energia dinâmica que é transferida para a composição de hastes no ensaio SPT pode ser calculada pelo uso da força incidente nas hastes em função do tempo, método $E F 2$, ou também pelo uso da força seccional e velocidade de partícula nas hastes, método EFV, como pode ser visto abaixo nas Equações 1 e 2.

$$
\mathrm{EF} 2=\frac{\mathrm{c}}{\mathrm{E} \times \mathrm{a}} \int_{0}^{\frac{2 \ell}{c}} \mathrm{~F}^{2}(t) d t
$$

\section{Em que:}

EF2 = energia transmitida à composição de hastes considerando o quadrado da força incidente nas hastes (J); $\mathbf{c}=$ velocidade teórica de propagação da onda ao longo da composição de hastes $(\mathrm{m} / \mathrm{s})$;

$\mathbf{E}=$ módulo de elasticidade do aço $(\mathrm{kPa})$;

$a=$ área da seção transversal instrumentada $\left(\mathrm{m}^{2}\right)$;

$\boldsymbol{\ell}=$ distância da seção instrumentada até o amostrador $(\mathrm{m})$;

$\mathbf{F}(\mathbf{t})=$ força seccional na haste $(\mathrm{kN})$;

$\mathbf{t}=$ tempo de integração (s).

$$
\mathrm{EFV}=\int_{0}^{\infty} \mathrm{F}(t) \times v(t) d t
$$

Em que:

EFV = energia transmitida à composição de hastes considerando a força seccional e a velocidade das partículas (J);

$\mathbf{F}(\mathbf{t})=$ força seccional na haste $(\mathrm{kN})$;

$\mathbf{v}(\mathbf{t})=$ velocidade das partículas $(\mathrm{m} / \mathrm{s})$;

$\mathbf{t}=$ tempo de integração (s).

O uso do método EFV é o mais indicado por apresentar maior consistência, pois considera a integral do sinal de força multiplicada pela integral da velocidade até o final da transferência de energia do martelo para as hastes $(\infty)$, a energia total transferida para as hastes representa a parcela da energia potencial do martelo que não se dissipou durante o processo de cravação. Esse método foi introduzido por Sy e Campanella (1991), utilizado em diversas pesquisas (CAVALCANTE, 2002; ODEBRECHT, 2003; HOWIE et al., 2003; AOKI et al., 2007; LUKIANTCHUKI, 2012; MORAIS, 2014; SANTANA, 2015) e é recomendado pela norma D4633-10 (ASTM, 2010) que regulamenta a medição de energia em ensaios SPT nos Estados Unidos, permitindo a determinação total da energia transferida do golpe de martelo para o ensaio SPT.

Caso tenha-se acesso apenas aos sinais de força, tem-se como opção utilizar o método EF2, mas sabendo que os resultados podem apresentar certo distanciamento da realidade (ODEBRECHT et al., 2005). Isso ocorre porque este método é na realidade uma simplificação realizada por Palacios (1977) e Schmertmann e Palacios (1979), devido à limitação da aferição da velocidade que havia na época. Para que se possa trabalhar com resultados obtidos por meio do método EF2 recomenda-se a utilização de fatores de correção que possibilitem a 
obtenção de resultados mais satisfatórios (LUKIANTCHUKI, 2012).

O método EF2 consiste em considerar que os impactos sucessivos que ocorrem entre a composição de hastes e o martelo, após o primeiro contato, não contribuem significativamente na penetração do amostrador no solo. Isso acontece, pois, o método considera apenas o intervalo no qual existe proporcionalidade entre os registros de força e de velocidade, tempo correspondente a $2 \ell / c$, e essa proporcionalidade só é válida para a primeira onda de compressão gerada pelo contato do martelo com as hastes do ensaio.

Portanto, a eficiência do ensaio SPT ( nEFV ou nEF2) pode ser calculada pela relação entre a energia transmitida à composição de hastes (EFV ou EF2) e a energia potencial teórica do ensaio $\left(E^{*}=m \cdot h \cdot g=478,20 \mathrm{~J}\right)$, conforme ilustrado na Equação 3 (LUKIANTCHUKI, 2012). Vale ressaltar que esse cálculo pode ser realizado para ambos os métodos e também considerando energias potenciais diferentes, como será visto a diante.

$$
\eta \mathrm{EFV}=\frac{\mathrm{EFV}}{\mathrm{E}^{*}}
$$

Em que:

nEFV = eficiência do ensaio utilizando-se 0 método EFV para medição de energia (\%);

$\mathbf{E}^{*}=$ energia potencial teórica $(\mathrm{J})$.

As primeiras pesquisas com o objetivo de medir a energia transferida ao conjunto de hastes no Brasil foram realizadas por Antônio Belincanta em meados de 1982. Por meio dos resultados de suas pesquisas Belincanta (1985) verificou a inconsistência do método EF2, quantificou o efeito que o uso de determinadas técnicas e equipamentos têm na eficiência do processo como, por exemplo, a utilização ou não de coxim de madeira, os tipos de cabeças de bater e o sistema de operação dos martelos (brasileiro e americano), e concluiu que os acelerômetros utilizados na época eram mais eficientes para hastes mais longas e rígidas. No início dos anos 2000, destacam-se no contexto nacional os trabalhos de Cavalcante (2002) e Odebrecht (2003).

Cavalcante (2002) em sua pesquisa, após análise de 1.130 golpes, concluiu que a energia transferida ao conjunto de hastes é independente do comprimento das hastes e da resistência do solo. Além disso, propôs um fator de correção para os valores de $\mathrm{N}_{\mathrm{SPT}}$ obtidos em ensaios com hastes de comprimento de até $14 \mathrm{~m}$.

No mesmo período Odebrecht (2003), utilizando dados próprios e os dados de Cavalcante (2002), desenvolveu vários estudos que visavam o monitoramento de energia no ensaio SPT. Entre suas principais contribuições têm-se a proposta de uma nova maneira de interpretação do ensaio SPT, fundamentada na consideração de que o SPT é um ensaio de grandes deslocamentos e, portanto, neste caso, o valor da penetração do amostrador no solo a cada golpe e a massa das hastes (além da do martelo) devem ser consideradas no cálculo da energia potencial disponível, conforme apresentado na Equação 4.

$$
\mathrm{EPG}=\mathrm{E}^{*}+\mathrm{M}_{\mathrm{m}} \mathrm{g} \rho+\mathrm{M}_{\mathrm{h}} \mathrm{g} \rho \quad \text { Eq.[4] }
$$

Em que:

EPG = energia potencial gravitacional calculada pelo método de Odebrecht (2003) (J);

$\mathbf{E}^{*}$ = energia potencial teórica $(\mathrm{J})$;

$\mathbf{M}_{\mathbf{m}}=$ massa do martelo $(\mathrm{kg})$;

$\mathbf{M}_{\mathbf{h}}=$ massa da composição de hastes $(\mathrm{kg})$.

$\boldsymbol{\rho}=$ penetração permanente do amostrador devido à aplicação de um golpe $(\mathrm{m})$;

$\mathbf{g}=$ aceleração da gravidade $\left(\mathrm{m} / \mathrm{s}^{2}\right)$

Observa-se que, para qualquer golpe que implique uma penetração no solo $(\rho)$, a energia potencial gravitacional do martelo é maior do que a energia potencial gravitacional teórica. Esta diferença é mais significativa quando o solo ensaiado apresenta menor resistência a penetração e, portanto, uma maior penetração a cada golpe. Considerando a penetração do amostrador no solo para o cálculo da energia também deve-se acrescentar o efeito que a massa da composição de hastes irá gerar quando deslocada de uma distância $\rho$, percebe-se que para maiores comprimentos da composição de hastes este efeito será mais acentuado. A Figura 1 apresenta um esquema que demonstra as variáveis e as considerações que compõem o método proposto por Odebrecht (2003). 


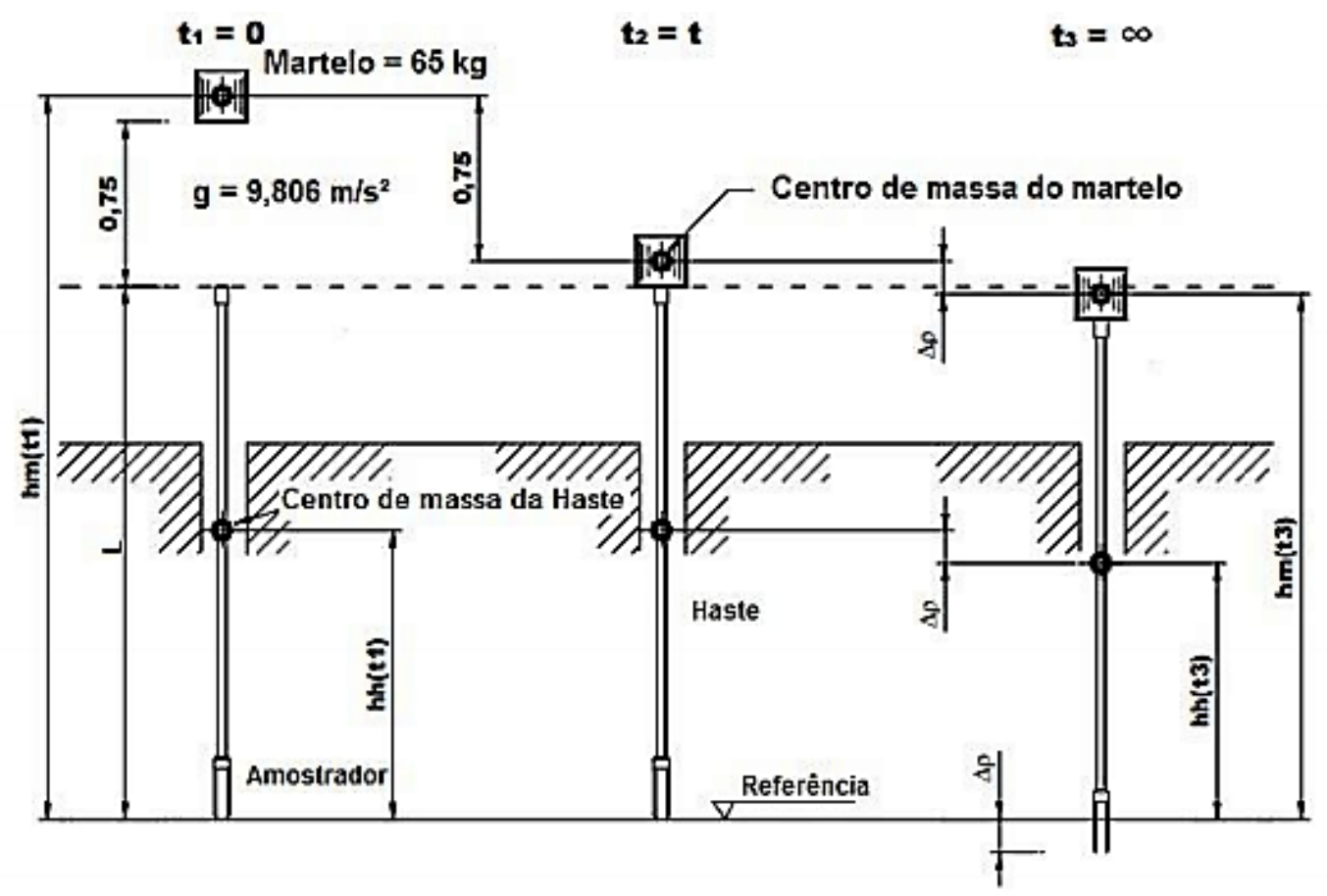

FIGURA 1: Energia potencial do sistema considerando o acréscimo da energia potencial do martelo e das hastes.

FONTE: Odebrecht (2003).

Para verificação da aplicabilidade da nova interpretação da energia, Odebrecht (2003) desenvolveu a Tabela 1, que apresenta uma relação entre o $\mathrm{N}_{\text {SPT }}$ e a profundidade, sendo que em algumas situações a correção da energia tradicional seria necessária e em outras não, ou seja, para valores de EPG/E* na ordem de 1,01 a 1,04 não seria necessário o cálculo da energia pelo seu método. Entretanto para valores na ordem de 1,10 (área hachurada mais escura) as diferenças se tornam significativas, tornando assim necessário o cálculo da energia pela nova interpretação.

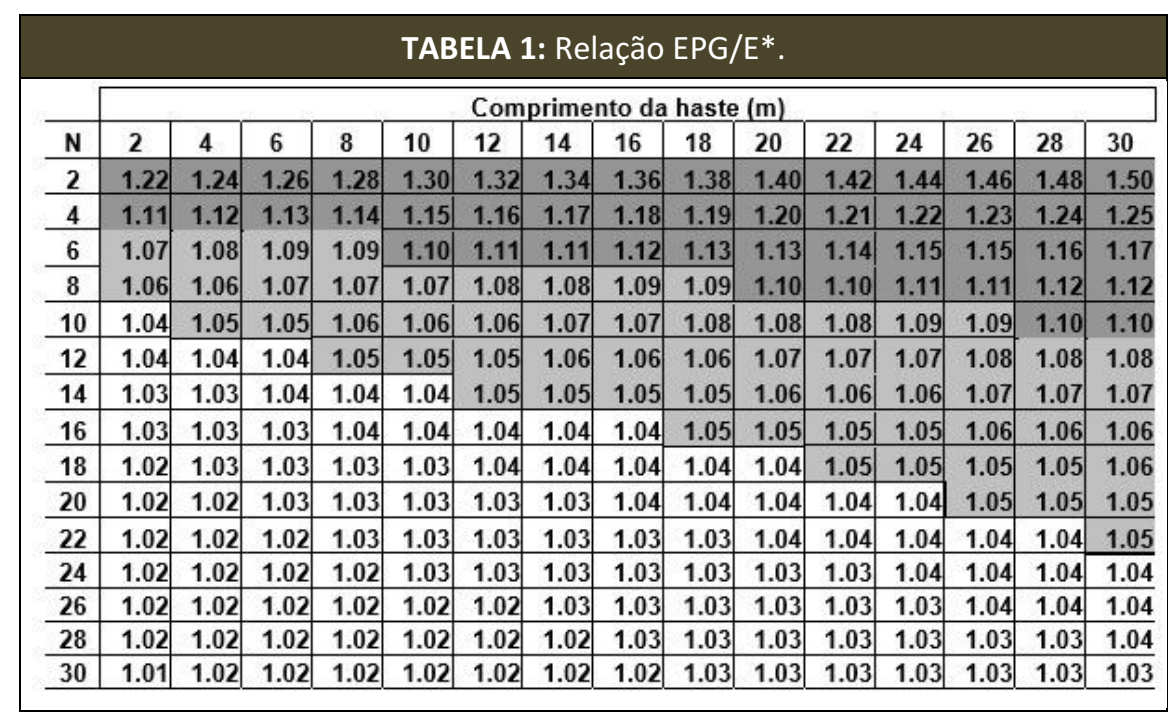

FONTE: Odebrecht (2003). 
Posteriormente aos trabalhos citados, têm-se ainda diversas pesquisas que estudam a medição de energia no ensaio SPT como, por exemplo, os trabalhos de Lukiantchuki (2012), Morais (2014), Santana (2015), Figueiredo (2016) e Lukiantchuki et al. (2017). Todos esses trabalhos concluem e recomendam a necessidade de se trabalhar com a medição de energia no ensaio SPT.

O meio utilizado para medição de energia no ensaio SPT pelos pesquisadores Cavalcante (2002) e Santana (2015) foi o equipamento comercial SPT Analyzer, fabricado pela Pile Dinamics, Inc (PDI). Esse equipamento permite a obtenção da energia referente à cada golpe, o registro do deslocamento vertical das hastes pelo operador e a evolução da energia com o tempo para o par de registros. O sistema admite a análise instantânea da qualidade dos sinais de aceleração e de deformação e o armazenamento dos dados para posterior análise e tratamento em um computador. Os demais pesquisadores citados desenvolveram seus próprios equipamentos de medição.

Cabe salientar que se encontra em fase de consulta pública uma versão revisada da norma brasileira NBR 6484 (ABNT, 2001) - Sondagens de Simples Reconhecimento com SPT, que contemplou a medição de energia no ensaio. Este fato evidencia a importância deste procedimento e corrobora para que continuem sendo realizados trabalhos abordando este tema.

\section{METODOLOGIA}

Para realizar essa pesquisa foram realizados dois furos de sondagem SPT, com medição de energia, no campo experimental da Escola de Engenharia Civil e Ambiental da UFG (ver Figura 2), com o apoio de empresa de geotecnia local. A escolha da área dos ensaios foi feita de forma a possibilitar futuras pesquisas no mesmo local, constituindo assim um campo experimental. As duas sondagens foram realizadas com uma distância de 1,95 metros entre elas e ambas atingiram a profundidade de 10,45 metros.

Para a medição da energia foi utilizado o equipamento comercial SPT Analyzer, fabricado pela Pile Dinamics, Inc (PDI). Esse equipamento é relativamente compacto e de fácil mobilização. Ele é constituído por uma unidade de aquisição de dados e um segmento de haste instrumentado com dois sensores de deformação (strain gauges) e dois furos para a fixação de dois acelerômetros diametralmente opostos. Os strain gauges e os acelerômetros permitem a aquisição de sinais de deformação e de aceleração, respectivamente. Os sinais de deformação e de aceleração permitem a obtenção da força e da velocidade que podem ser utilizadas para calcular a eficiência de energia do ensaio SPT (PDI, 1995).

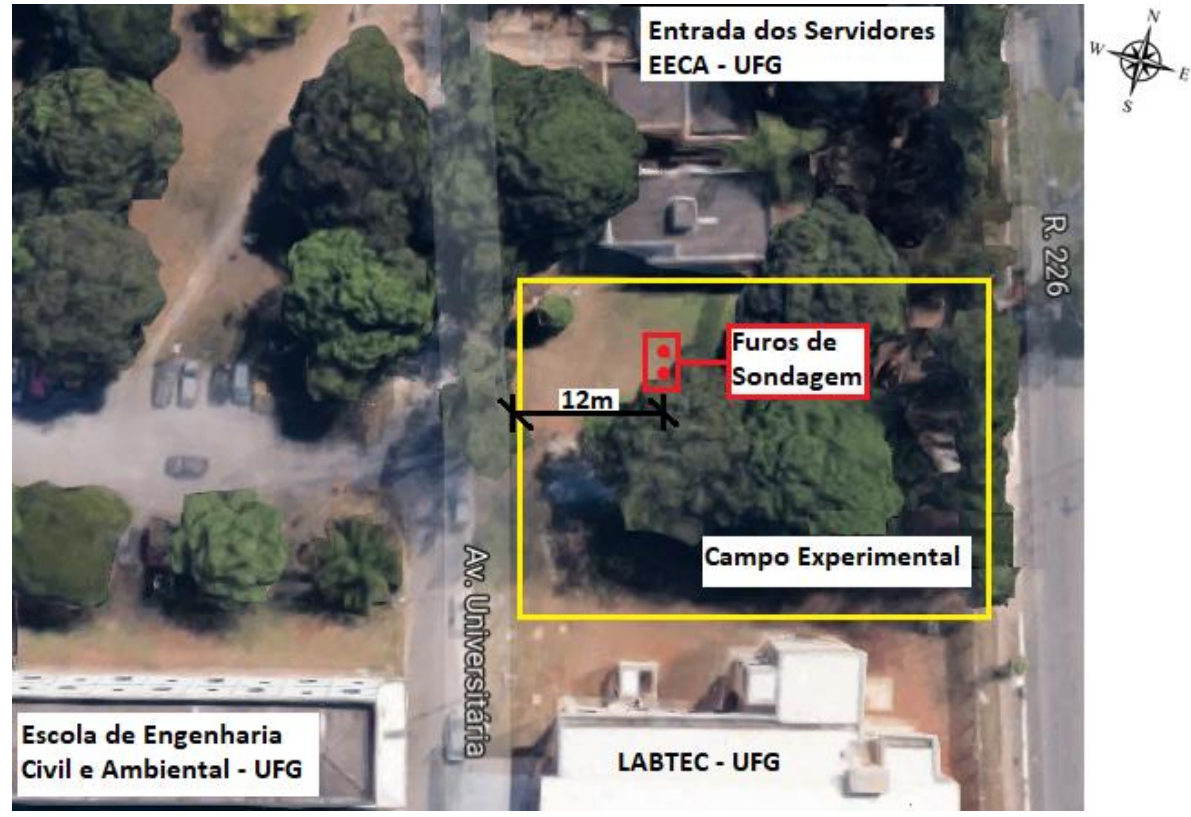

FIGURA 2: Imagem com localização dos furos de sondagem na área do Campo Experimental da EECA-UFG. FONTE: Adaptado de Google Maps (2017). 
A equipe de sondagem era composta por três integrantes e estava munida com os equipamentos apresentados na Figura 3:

a) Martelo: cilíndrico, maciço, com coxim de madeira desgastado, com pino guia e massa de $64,72 \mathrm{~kg}$;

b) Cabeça de bater: cilíndrica, maciça e com massa de 3,94 kg;

c) Sistema de levantamento e soltura do martelo: levantamento manual com cabo de aço por meio de polias e soltura do martelo por meio de gatilho manual tipo Furnas;

d) Hastes: metálicas, conservadas e com massa de $3,16 \mathrm{~kg} / \mathrm{m}$;

e) Amostrador: tipo Raymond bipartido, conservado e com massa de 6,42 kg;

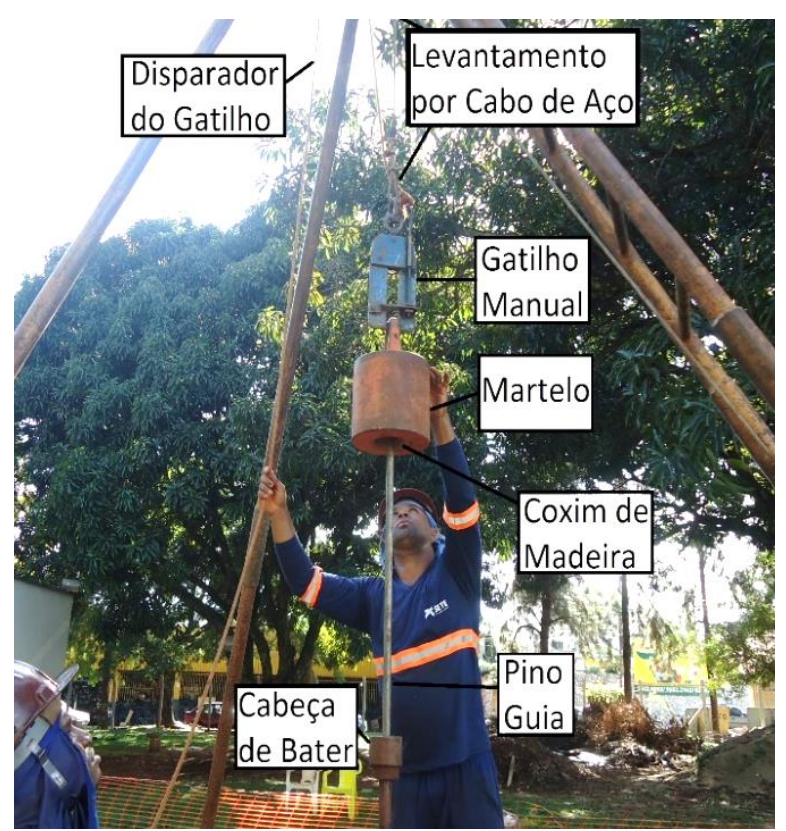

FIGURA 3: Equipamentos utilizados para realização do ensaio.

FONTE: Autoria Própria.

Os furos de sondagem foram executados seguindo as orientações da NBR 6484 (ABNT, 2001), que padroniza a execução do ensaio SPT. O primeiro metro foi perfurado com auxílio de trado concha e posteriormente foi realizada a cravação do amostrador nos $45 \mathrm{~cm}$ iniciais por meio de queda do martelo na cabeça de bater, sendo que durante essa fase foi feito o monitoramento da energia de cada golpe por meio de sensores que integram o analisador de ondas dinâmicas. A partir da profundidade de $6,45 \mathrm{~m}$, para ambos os furos, foi necessário iniciar a fase de avanço com circulação de água devido à coesão do solo não possibilitar que ele fosse retirado do furo e a maior resistência da camada de solo não permitir o avanço por trado.

Durante a medição da energia foram utilizados os seguintes equipamentos:

a) Unidade de aquisição de dados: caixa compacta com dimensões de $20,5 \mathrm{~cm} \times 17,5 \mathrm{~cm} \times 11,5 \mathrm{~cm}$ com tela sensível ao toque e canal para aquisição de dados;

b) Bateria externa recarregável $12 \mathrm{~V}-4500 \mathrm{~A}$;

c) Cartão de memória de $40 \mathrm{MB}$ para registro de dados;

d) Cabos de conexão impermeabilizados de 30 metros;

e) Haste instrumentada dotada de medidores de deformação (strain gauges) sensíveis a 0,01 $\mu \epsilon$ e 0,20 Volts;

f) Par de acelerômetros piezoeléctricos, sensíveis à voltagem da ordem de $1,0 \mathrm{mV} / \mathrm{g}$ e capazes de registrar aceleração de até $10.000 \mathrm{~g}$., protegidos em blocos de alumínio com dimensões de $3,0 \mathrm{~cm} \times 3,0 \mathrm{~cm} \times 1,8 \mathrm{~cm}$ e acoplados a haste instrumentada por meio de parafusos.

Para monitoramento dos golpes foi acoplada à extremidade superior da composição de hastes do ensaio a haste instrumentada com strain gauges e com os dois acelerômetros instalados, ver Figura 4. Esses sensores foram conectados à unidade de aquisição de dados por meio de cabos para prolongação da ligação entre a haste e a unidade de aquisição de dados. Os sinais registrados na unidade de aquisição de dados foram monitorados em tempo real a cada golpe do martelo. Cada registro foi composto de dois sinais de força e dois de velocidade, referentes aos pares de strain gauges e de acelerômetros, respectivamente.

Cabe ressaltar que foi realizado o registro manual da penetração do amostrador no solo pela medida da marcação na haste após cada golpe, usando apenas um único referencial (para garantir a precisão da penetração) e o registro do tamanho da amostra no interior do amostrador, inclusive o bico (esse tamanho é denominado êmbolo), como representado na Figura 5. 


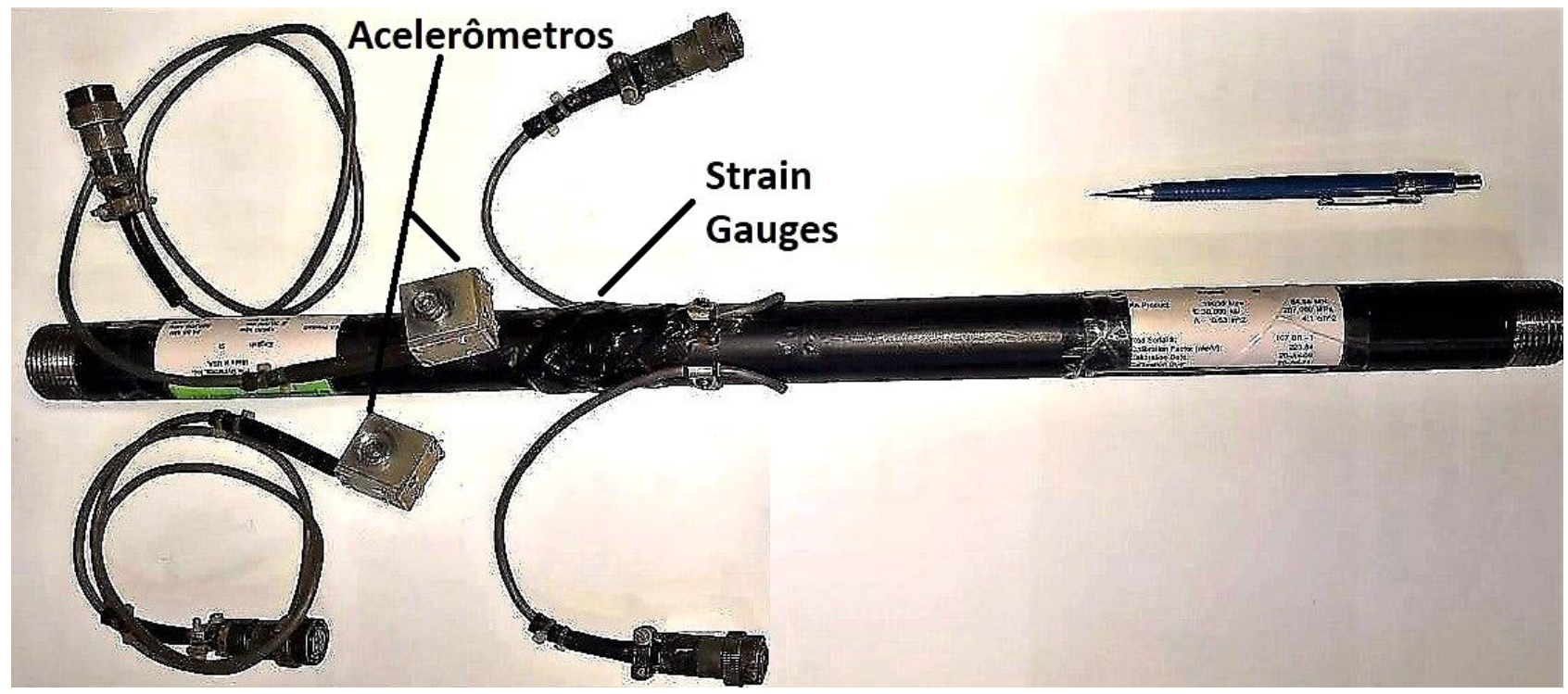

FIGURA 4: Haste instrumentada. FONTE: Autoria Própria.

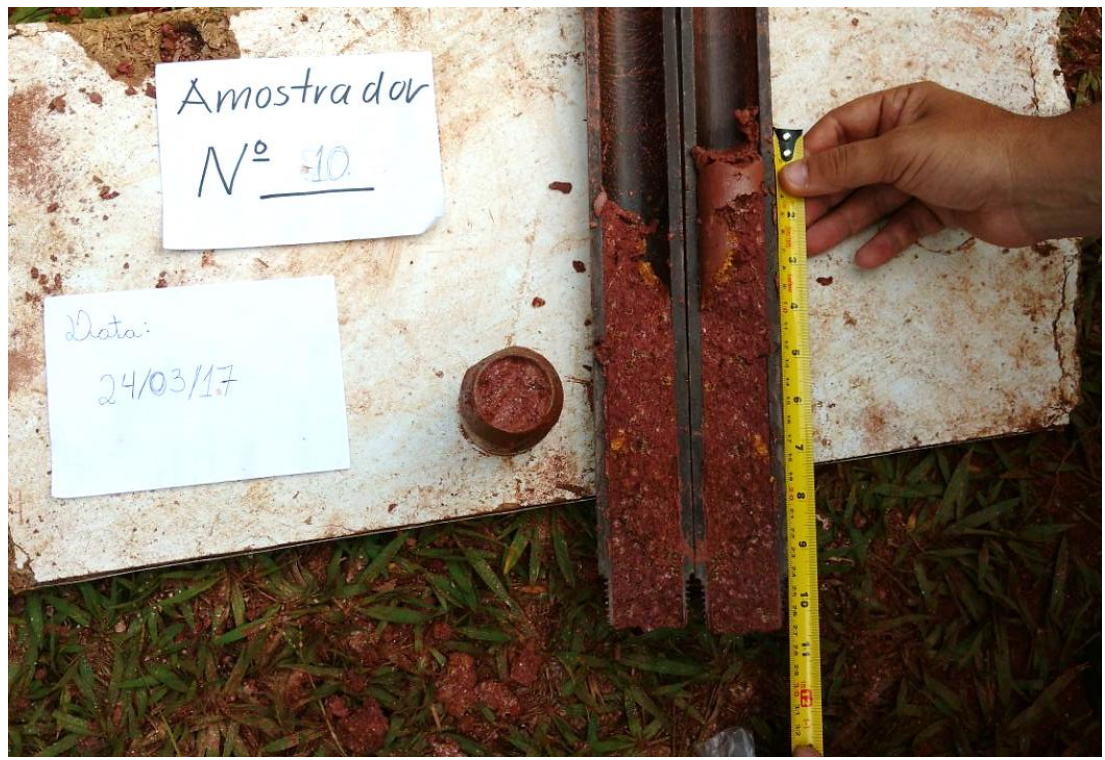

FIGURA 5: Retirada de solo do amostrador e medição do êmbolo.

FONTE: Autoria Própria.

Foi realizada a caracterização táctil visual das amostras de solo, a determinação do teor de umidade e da compacidade/consistência das amostras de solo do perfil de ambos os furos de sondagem. A caracterização táctil visual foi realizada conforme a norma de Identificação e Descrição de Amostras de Solos obtidas em sondagens de simples reconhecimento do solo, NBR7250 (ABNT,1982).

Os dados de energia do ensaio coletados pela unidade de aquisição de dados de SPT foram salvos no cartão de memória do equipamento, posteriormente os dados desse cartão foram descarregados em software de análise dinâmica comercial, que é capaz de realizar a leitura e tratamento dos dados.

Todos os dados obtidos durantes os ensaios foram transferidos e tratados em planilhas eletrônicas. Onde para cada ensaio SPT foram compilados os valores de profundidade, número dos golpes, penetração do amostrador a cada golpe, N $\mathrm{N}_{\text {SPT }}$, tipo de solo, umidade, compacidade, tamanho do êmbolo de solo no amostrador (recuperação da amostra), força, velocidade, EFV, $E F 2$, eficiência de energia convencional e eficiência da energia por Odebrecht (2003). Estas planilhas, apresentadas por Jardim; Machado; Jorge (2017), compõem o banco de dados deste estudo. 


\section{RESULTADOS E ANÁLISES}

Os resultados obtidos de resistência à penetração $\mathrm{N}_{\mathrm{SPT}}$ e de caracterização táctil-visual do solo, apresentados no Quadro 1, são importantes para melhor compreensão do ensaio SPT e para verificar a influência destes fatores nos valores de energia e, consequentemente, de eficiência do ensaio. Faz-se a observação para o primeiro metro do furo de sondagem SPO1 que apresentou valor de $\mathrm{N}_{\text {SPT }}$ relativamente maior ao do furo SPO2 devido a presença de raiz de uma das árvores próximas ao furo. Destaca-se que durante a realização dos dois furos de sondagem não foi encontrado o nível d'água.
A classificação dos solos recolhidos para amostra de ambos os furos de sondagem demonstrou que se tratam de materiais semelhantes. Os valores de $\mathrm{N}_{\text {SPT }}$ com diferença considerável nas profundidades intermediárias (entre 4,0 e 7,0 metros) deve-se à presença de fragmentos de pedregulhos encontrados no furo de sondagem SP01.

A Figura 6 permite a visualização do valor de $\mathrm{N}_{\text {SPT }}$ em função da profundidade no perfil paras os dois furos de sondagem SP01 e SP02.

As Figuras 7 e 8 apresentam a variação da energia EFV, em termos de valores máximos e mínimos, e o ponto médio desses valores, para cada etapa de cravação dos furos de sondagem SP01 e SP02.

\begin{tabular}{|c|c|c|c|c|c|c|c|}
\hline Prof. (m) & \multicolumn{3}{|c|}{ SP01 } & \multicolumn{3}{|c|}{ SP02 } & Classificação do Solo \\
\hline 0,00 a 1,00 & $\begin{array}{c}\text { Nspt } \\
\text { (golpes) }\end{array}$ & $\begin{array}{c}\text { Êmbolo } \\
\text { (cm) }\end{array}$ & $\begin{array}{c}\text { Umidade } \\
(\%)\end{array}$ & $\begin{array}{c}\text { NsPt } \\
\text { (golpes) }\end{array}$ & $\begin{array}{c}\text { Êmbolo } \\
(\mathrm{cm})\end{array}$ & $\begin{array}{c}\text { Umidade } \\
(\%)\end{array}$ & \multirow{2}{*}{$\begin{array}{l}\text { Areia siltosa, marrom, amarelada } \\
\text { e pouco compacta }\end{array}$} \\
\hline 1,00 a 2,00 & 6 & 7 & $18 \%$ & 2 & 24 & $18 \%$ & \\
\hline 2,00 a 3,00 & 11 & 36 & $13 \%$ & 15 & 23,5 & $14 \%$ & $\begin{array}{l}\text { Areia siltosa com pedregulhos } \\
\text { (fragmentos de quartzo) e } \\
\text { compacidade de relativamente a } \\
\text { medianamente compacta }\end{array}$ \\
\hline 3,00 a 4,00 & 4 & 36 & $4 \%$ & 3 & 19 & $4 \%$ & $\begin{array}{l}\text { Transição } \\
\text { transportado e solo residual - }\end{array}$ \\
\hline 4,00 a 5,00 & 8 & 39 & $10 \%$ & 3 & 30,5 & $14 \%$ & $\begin{array}{l}\text { Areia siltosa com pedregulhos } \\
\text { (fragmentos de quartzo) e } \\
\text { compacidade de fofa a } \\
\text { medianamente compacta }\end{array}$ \\
\hline 5,00 a 6,00 & 13 & 41 & $10 \%$ & 4 & 24,5 & $16 \%$ & $\begin{array}{l}\text { Solo Residual Jovem - Silte } \\
\text { arenoso, micáceo marrom e }\end{array}$ \\
\hline 6,00 a 7,00 & 18 & 39 & $9 \%$ & 3 & 30 & $10 \%$ & $\begin{array}{l}\text { compacidade de fofa a } \\
\text { medianamente compacta }\end{array}$ \\
\hline 7,00 a 8,00 & 13 & 33 & $18 \%$ & 13 & 26,5 & $28 \%$ & \\
\hline 8,00 a 9,00 & 8 & 28 & $29 \%$ & 16 & 25 & $24 \%$ & $\begin{array}{l}\text { Solo Residual Jovem - Silte } \\
\text { arenoso, micáceo marrom com }\end{array}$ \\
\hline 9,00 a 10,00 & 11 & 34 & $33 \%$ & 12 & 23,5 & $31 \%$ & $\begin{array}{l}\text { esverdeadas e medianamente } \\
\text { compacta }\end{array}$ \\
\hline 10,00 a 11,00 & 13 & 31 & $26 \%$ & 13 & 34 & $24 \%$ & \\
\hline
\end{tabular}




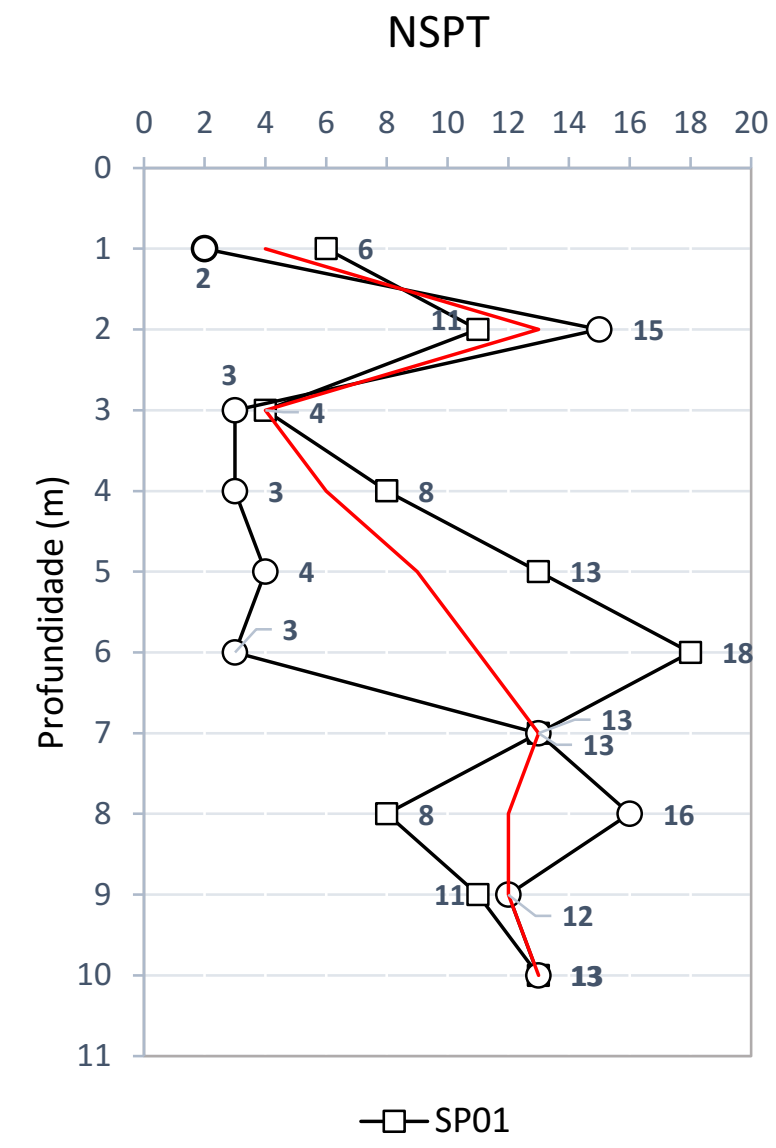

FIGURA 6: Valor de NSPT versus profundidade (m) FONTE: Autoria Própria.

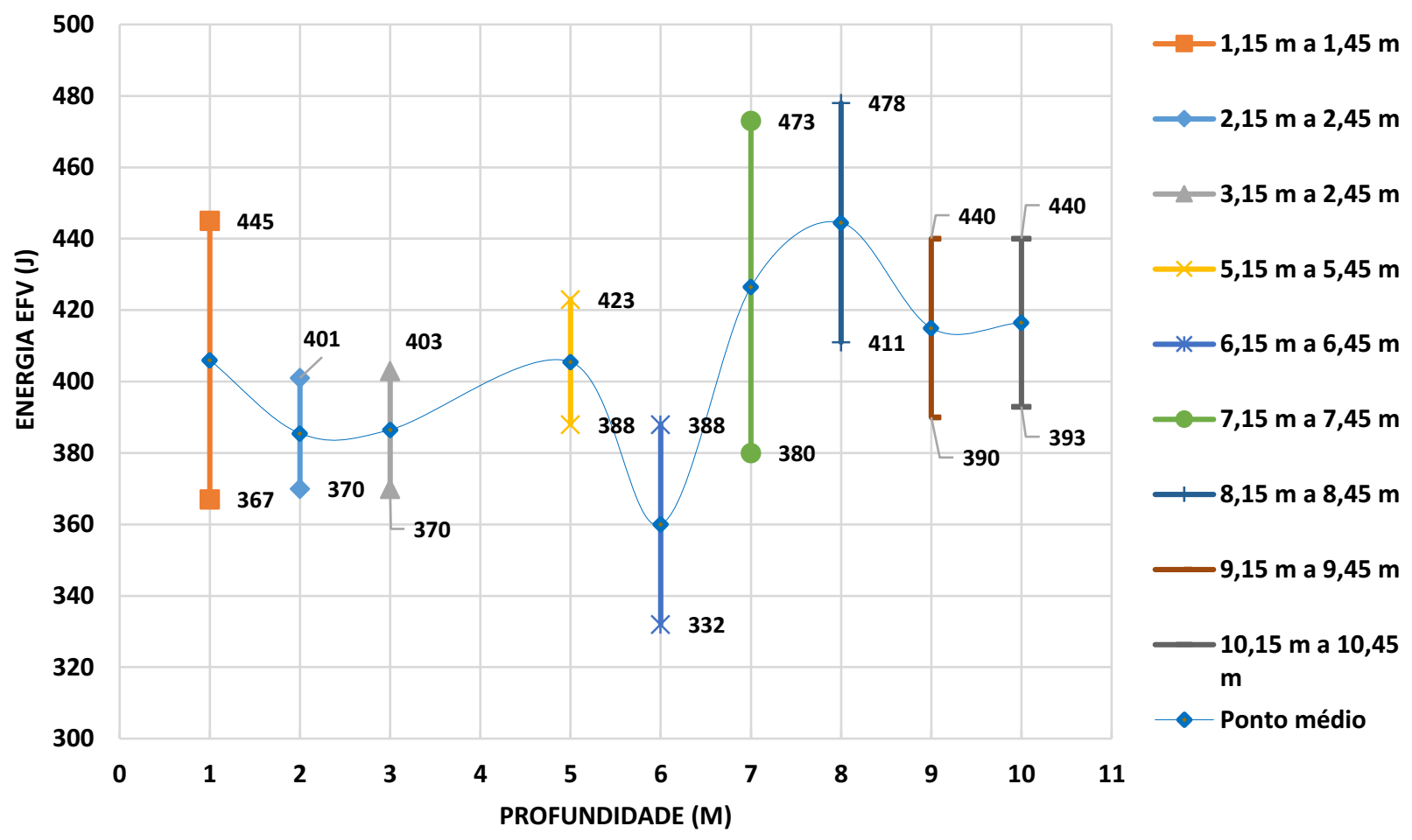

FIGURA 7: Gráfico da Energia EFV (J)X Profundidade $(\mathrm{m})$ do SP01 FONTE: Autoria Própria. 


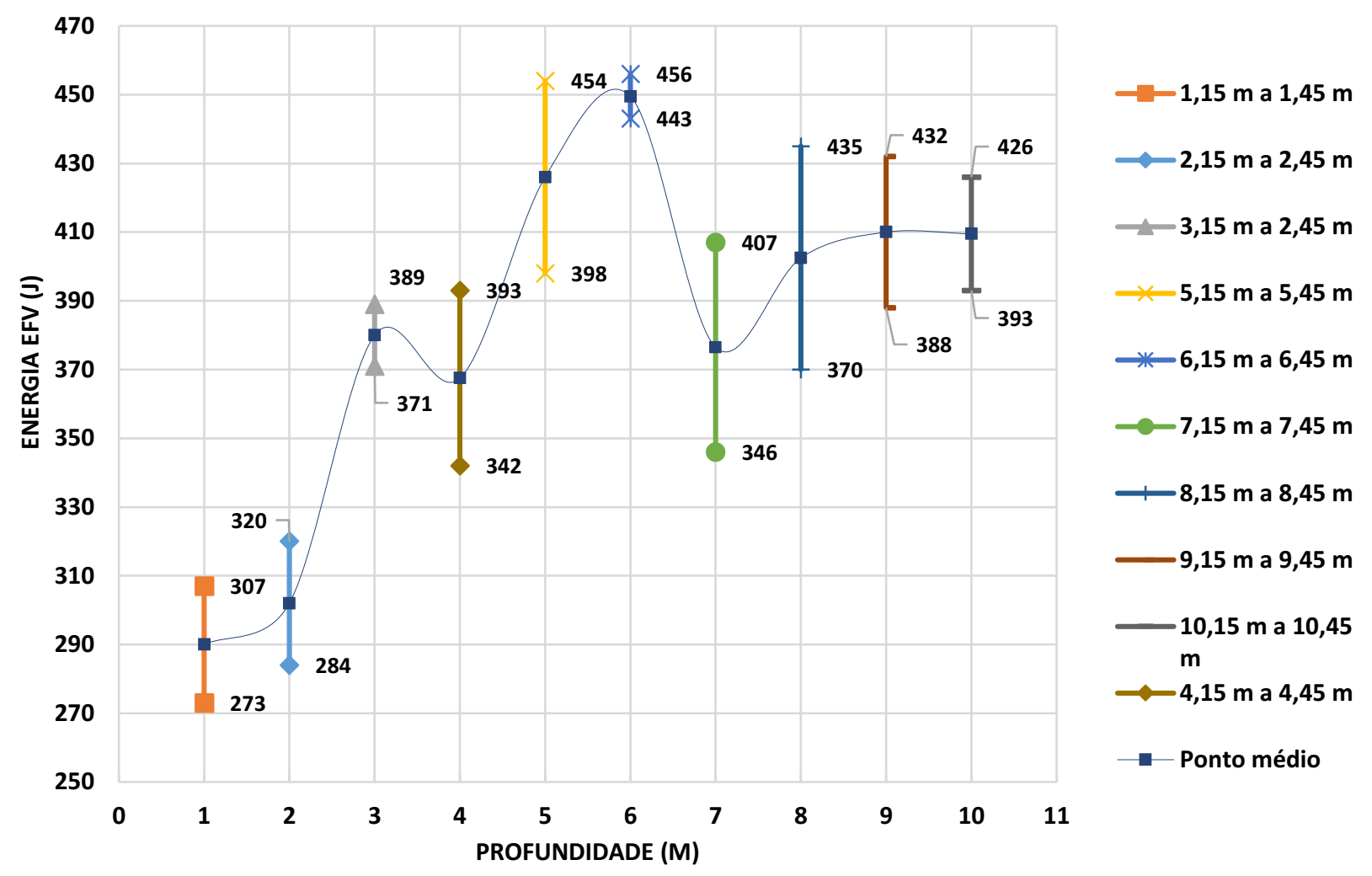

FIGURA 8: Gráfico da Energia EFV (J)X Profundidade (m) do SP02 FONTE: Autoria Própria.

Apesar dos dois furos de sondagem distarem apenas 1,95 metros e do fato de ambos terem sido realizados pela mesma equipe $\mathrm{e}$ equipamentos de sondagem, verificou-se resultados superiores de $\mathrm{N}_{\mathrm{SPT}}$, principalmente para o trecho entre 4 e 7 metros de profundidade para o furo SP01, este fato pode ser explicado neste estudo pela presença de fragmentos de pedregulhos nas referidas camadas. Os valores maiores do êmbolo e os menores do teor de umidade corroboram para existência de material menos deformável e de menor capacidade de retenção de umidade, característico de pedregulhos/fragmentos. Embora não seja desejável, a ocorrência de diferenças significativas nos valores de NSPT em furos próximos não é situação incomum, caso semelhante também foi relatado no estudo de Santana e Danziger (2016).

Dos 253 golpes realizados durante os ensaios SPT apenas 10 não foram monitorados pelo analisador de ondas dinâmicas, devido a problemas técnicos (surgimento de folga na fixação dos acelerômetros) envolvendo a haste instrumentada.
Esses 10 golpes são referentes ao ensaio SP01 e ocorreram nas profundidades de 4 metros (energia de 8 golpes perdidas) e 8 metros (energia de 2 golpes perdidas). Devido às perdas citadas a energia aos 4 metros para o ensaio SP01 não foi considerada nas análises. Já do restante dos 243 golpes que foram registrados pelo analisador de ondas dinâmicas durante os dois ensaios 63 registros não foram utilizados nas análises dos dados. Esses foram desconsiderados devido ao fato de que estes golpes eram referentes aos $15 \mathrm{~cm}$ iniciais de cada etapa de cravação e como os $15 \mathrm{~cm}$ iniciais não são utilizados para o cálculo do $\mathrm{N}_{\mathrm{SPT}}$, optou-se por não considerará-los no cálculo de energia, já que estes dois parâmetros seriam correlacionados. Essa mesma consideração também foi feita em trabalhos anteriores, como é o caso dos realizados por Belincanta (1998) e Cavalcante; Danziger; Danziger (2011). Cabe salientar que todos os resultados de medição de energia deste estudo foram compilados para cada golpe do ensaio SPT, formando um banco de dados apresentado em Jardim; Machado; Jorge (2017). 
Cada golpe registrado durante as sondagens SPT foi posteriormente analisado em software de análise dinâmica que gerou os gráficos da variação de velocidade e força para cada golpe e forneceu os valores de energia pelos métodos EF2 e EFV, a constante FVP, que quantifica a relação da força com a velocidade durante o golpe e a eficiência de energia (ETR) para cada golpe considerando-se o método EFV. A Figura 9 ilustra um gráfico típico obtido para um determinado golpe do Ensaio no furo de sondagem SP02.

A Figura 9 apresenta uma sequência de pulsos sucessivos de compressão, sendo que o maior corresponde ao impacto inicial do martelo sobre a composição de hastes que ocorre no tempo $2 \ell /$ c. Para a composição de hastes utilizada no Brasil, com impedância bastante inferior à do amostrador encontra-se em análises como essas várias reflexões de compressão, situações similares as essas foram relatadas por Cavalcante (2002) e Figueiredo (2016). Os demais pulsos são gerados devido aos contatos subsequentes do martelo com a cabeça de bater após o primeiro golpe (repique) e da energia potencial do martelo que não é transmitida totalmente à composição de hastes.

É importante evidenciar que cada pulso está relacionado a um acréscimo de penetração do amostrador no solo. O gráfico também demonstra a validade do método EFV, pois mostra que a penetração do amostrador no solo não é função exclusiva do primeiro impacto do martelo na cabeça de bater, como considera o método EF2. A Figura 10, abaixo, exibe três outros gráficos de variação da força e da velocidade no tempo.

Furo de Sondagem SP02 - Forca x Velocidade

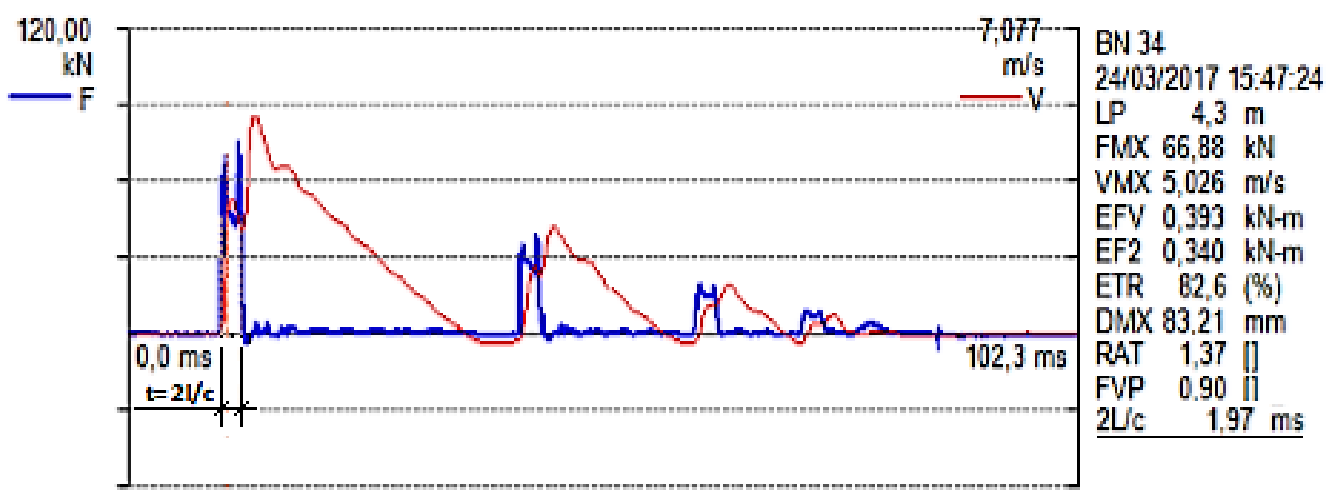

FIGURA 9: Gráfico da força e velocidade no tempo. FONTE: Autoria Própria. 


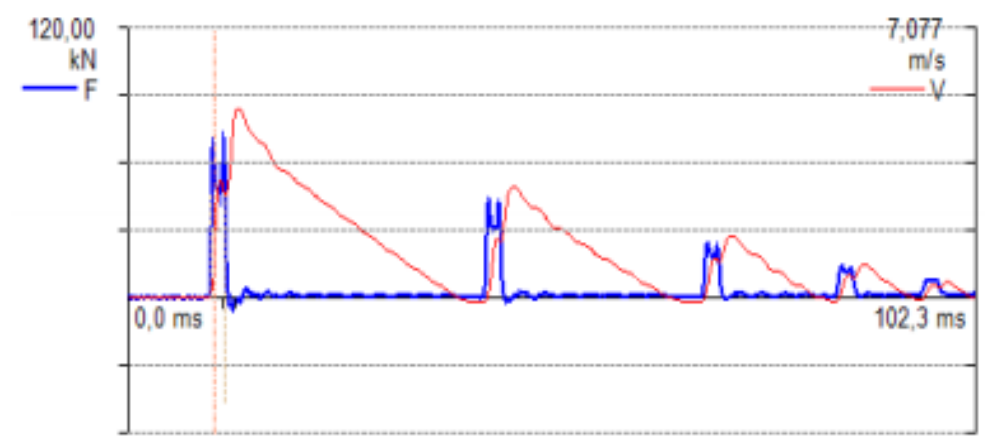

[a]

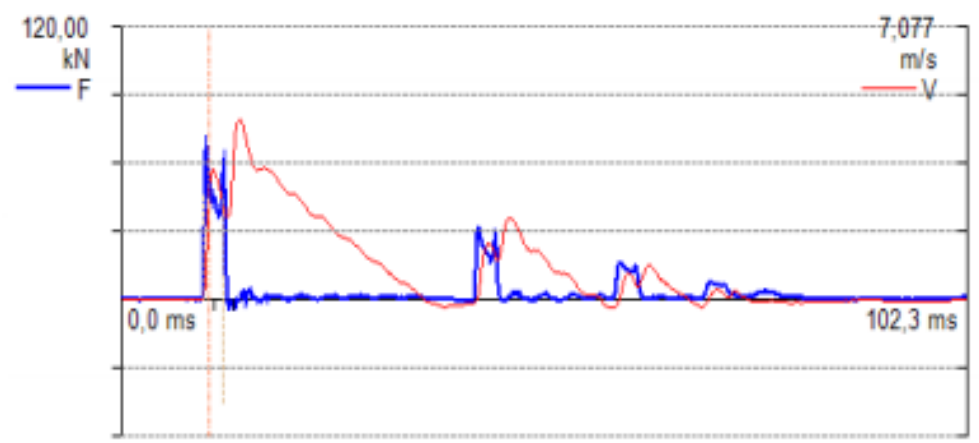

[b]

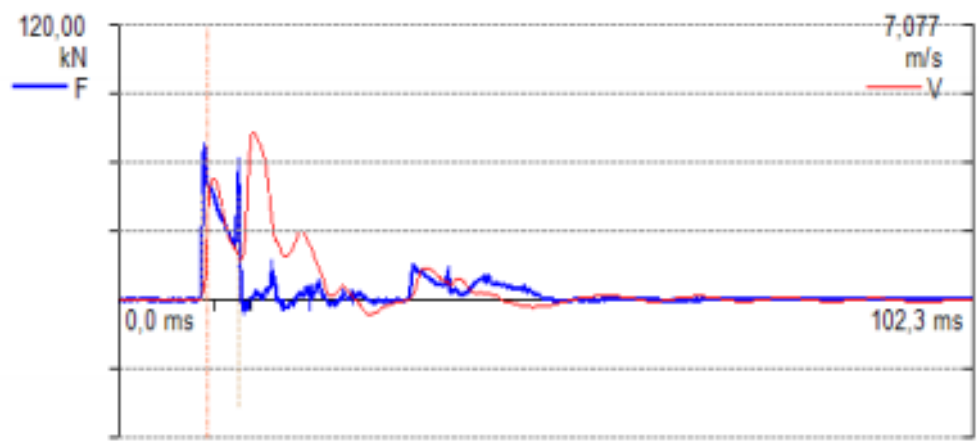

[c]

FIGURA 10: Gráficos da força e velocidade no tempo: [a] profundidade de 3 metros;

[b] profundidade de 5 metros; [c] profundidade de $10 \mathrm{~m}$. FONTE: Autoria Própria.

Analisando a sequência de gráficos expostos na Figura 10 observa-se que, com o aumento da profundidade do furo, a parcela de energia absorvida no primeiro impacto se torna maior e assim mais significativa em relação aos demais pulsos para o cálculo da eficiência do ensaio SPT. Na Figura 10[a] (profundidade $3 \mathrm{~m}$ ) percebe-se quatro pulsos sucessivos após o primeiro impacto, já na Figura 10[b] (profundidade $5 \mathrm{~m}$ ) nota-se apenas três pulsos e, por fim, na Figura 10[c] (profundidade $10 \mathrm{~m}$ ) podemos admitir que após o impacto inicial os efeitos subsequentes são desprezíveis. Essa análise demonstra que com o aumento da profundidade os métodos EFV e EF2 tendem a aproximar seus resultados. Entretanto, essa similaridade ocorre apenas para condições específicas, portanto, é necessário ter atenção na utilização do método EF2.

Os resultados de energia EFV e EF2 obtidos para cada golpe foram utilizados para o cálculo da média de eficiência de energia para cada etapa de cravação ( $\mathrm{nEFV}$ e nEF2), considerando a energia teórica $\left(E^{*}\right)$ calculada pela fórmula tradicional (produto da massa do martelo pela aceleração da gravidade pela altura de queda do martelo) e pela energia calculada pelo método de Odebrecht (EPG), conforme ilustrado na Tabela 2. 
TABELA 2: Eficiências e Energias Teóricas.

\begin{tabular}{|c|c|c|c|c|c|c|c|c|c|c|}
\hline \multirow{3}{*}{$\begin{array}{l}\text { Profundidade } \\
\text { (m) }\end{array}$} & \multicolumn{4}{|c|}{ Energia Teórica do Ensaio $\left(E^{*}\right)=475,96 \mathrm{~J}$} & \multicolumn{6}{|c|}{ Energia Odebrecht (EPG) via Eq. 4} \\
\hline & \multicolumn{2}{|c|}{ Ensaio SP01 } & \multicolumn{2}{|c|}{ Ensaio SP02 } & \multicolumn{3}{|c|}{ Ensaio SP01 } & \multicolumn{3}{|c|}{ Ensaio SP02 } \\
\hline & nEFV (\%) & nEF2 (\%) & nEFV (\%) & nEF2 (\%) & EPG (J) & nEFV (\%) & nEF2 (\%) & EPG (J) & nEFV (\%) & nEF2 (\%) \\
\hline 1,0 a 1,45 & 88,1 & 35,1 & 60,9 & 46,1 & 506,6 & 82,7 & 33,0 & 593,6 & 45,3 & 34,3 \\
\hline 2,0 a 2,45 & 81,8 & 58,3 & 63,7 & 60,1 & 498,4 & 78,1 & 55,6 & 490,8 & 47,4 & 44,7 \\
\hline 3,0 a 3,45 & 81,3 & 63,0 & 79,3 & 67,1 & 542,0 & 71,4 & 55,3 & 555,8 & 59,0 & 49,9 \\
\hline 4,0 a 4,45 & - & - & 87,1 & 71,6 & - & - & - & 556,1 & 64,8 & 53,3 \\
\hline 5,0 a 5,45 & 85,2 & 80,6 & 88,6 & 75,0 & 495,9 & 81,8 & 77,4 & 540,5 & 66,0 & 55,8 \\
\hline 6,0 a 6,45 & 74,9 & 85,6 & 94,5 & 81,6 & 491,3 & 72,0 & 82,9 & 573,9 & 70,4 & 60,7 \\
\hline 7,0 a 7,45 & 84,4 & 85,2 & 76,8 & 90,6 & 498,0 & 68,0 & 68,6 & 497,3 & 57,2 & 67,4 \\
\hline 8,0 a 8,45 & 91,6 & 83,3 & 82,4 & 94,5 & 508,3 & 85,8 & 78,0 & 492,7 & 61,3 & 70,3 \\
\hline 9,0 a 9,45 & 86,8 & 91,7 & 86,3 & 94,9 & 500,2 & 82,6 & 87,3 & 501,4 & 64,2 & 70,6 \\
\hline 10,0 a 10,45 & 86,5 & 94,6 & 85,7 & 96,5 & 499,5 & 82,4 & 90,2 & 496,3 & 63,8 & 71,8 \\
\hline n Média & 84,5 & 75,3 & 80,5 & 77,8 & 504,5 & 78,3 & 69,8 & 529,8 & 59,9 & 57,9 \\
\hline CV (\%) & 6 & 26 & 13 & 22 & 3 & 8 & 27 & 7 & 13 & 22 \\
\hline
\end{tabular}

Décourt et al. (1989) afirma que a eficiência do SPT brasileiro é em média $72 \%$. Considerando que esse valor tenha sido determinado em termos do método $E F 2$, verifica-se que as médias dos furos de sondagem SP01 e SP02 ficaram próximas desse valor, com $75,3 \%$ e $77,8 \%$ respectivamente. Já Cavalcante (2002), utilizando o método EFV, obteve uma eficiência média de $81 \%$ para o ensaio SPT brasileiro, valor também próximo dos medidos no presente trabalho, $84,5 \%$ para o ensaio SP01 e $80,5 \%$ para o ensaio SP02.

Analisando a Tabela 2 constata-se que o método EF2 apresenta valores maiores quão maior é o comprimento da composição de hastes. Esse fato já havia sido relatado em trabalhos anteriores como o de Morgano e Liang (1992), o que ocorre devido ao fato desse método considerar apenas a energia transferida até o tempo $2 \ell / c$. Cavalcante (2002) afirma que para comprimentos a partir de 10 metros, a transferência de energia transcorre quase que completamente no primeiro impacto, o que faz com que os valores de EF2 e EFV da Tabela 2 terem se aproximado gradualmente, conforme aumentou-se a composição de hastes. Segundo Morgano e Liang (1992), para ensaios SPT realizados em profundidades entre 12 e 15 metros houve maior correspondência entre os dois métodos de determinação da eficiência da energia.

Em complementação, também foi calculada a eficiência média dos dois ensaios, tanto pelo método tradicional quanto pelo método de Odebrecht (2003), essas eficiências estão dispostas na Tabela 2. A eficiência média foi calculada por meio da média de eficiência de todos os golpes considerados no estudo.

Observando a média de energia e os coeficientes de variação dos ensaios apresentados na Tabela 2 verificou-se que os valores médios de energia gerados pelo método EFV são relativamente superiores aos do método EF2 para os ensaios realizados no furo de sondagem SP01, para os comprimentos de hastes utilizados neste estudo e para o $\mathrm{N}_{\text {SPT }}$ obtido, este é um resultado considerado normal, pois como aferiu Butler et al. (1998) e pôde-se ser percebido na Tabela 2, o método EF2 sofre uma maior variação da sua gama de valores, durante os 10 primeiros metros de ensaio, em relação ao método EFV. Em contraposição ao observado, os resultados médios obtidos para os ensaios em SP02 de eficiência para o método EF2 são superiores ao método EFV, fato mais incomum, todavia, isso pode ser explicado 
pelo fato de que nos últimos metros do furo de sondagem SPO2 encontrou-se camadas de solo relativamente mais resistentes do que no furo de sondagem SP01, como pode-se verificar na Tabela 2. Vale ressaltar que o método EF2 apresenta valores bastante elevados para solos mais resistentes e composições de hastes maiores (HOWIE, 2003).

Ainda na Tabela 2 têm-se as eficiências de energia obtidas pelo método de Odebrecht (2003), os valores obtidos por esse método são relativamente menores que os valores calculados utilizando a energia potencial teórica. Esse comportamento é verificado, pois o método de Odebrecht (2003) considera a altura de penetração no solo e a massa da composição de hastes para o cálculo de uma nova energia potencial, essa consideração faz com que a energia potencial considerada para cada golpe seja maior do que a energia potencial teórica do ensaio e, portanto, forneça eficiências menores.

A eficiência média calculada pelo método de Odebrecht (2003), considerando o método EFV, obteve um valor 7,35\% menor que o método tradicional para o ensaio SP01 e $25,6 \%$ para o ensaio SP02. Como foi apresentado na seção 3, o método de Odebrecht (2003) é bastante sensível às variações na resistência dos solos, observando a Figura 6 percebe-se uma mudança na resistência das camadas intermediárias do perfil do solo (entre 3 e 6 metros) do ensaio SP02 em relação ao ensaio SP01.

As Tabelas 3 e 4 corroboram com os resultados apresentados no parágrafo anterior porque utilizam-se da técnica criada por Odebrecht (2003), que foi apresentada na Tabela 1, para avaliar a necessidade ou não de se considerar o ensaio como um fenômeno de grandes deslocamentos. Percebe-se que para a Tabela 4, nas profundidades de 3,0 a 6,0 metros, há uma grande discrepância entre a energia teórica e a energia calculada por Odebrecht (2003). Ambas as Tabelas apresentam hachurados os valores que indicam uma discrepância maior que $10 \%$ entre as energias.

Para os ensaios em SP01 a Tabela 3 demonstra que apenas uma etapa de cravação apresentou um baixo valor de $\mathrm{N}_{\mathrm{SPT}}$ (de 3,0 a 3,45 metros), resistências inferiores a 4 golpes, o que consequentemente gerou uma diferença de $14 \%$ entre os dois métodos de se calcular a energia potencial, mas no geral os valores obtidos apresentaram uma boa correspondência, com diferenças entre 3\% e 7\%. Portanto, para o Ensaio 1, é razoável utilizar a energia potencial teórica para o cálculo da eficiência média do ensaio, o que gera uma diferença percentual de 7,35\%. Isso ocorreu, pois, o solo não apresentou baixos valores de $\mathrm{N}_{\text {SPT }} \mathrm{e}$ o ensaio não progrediu para maiores profundidades.

Todavia, para o Ensaio SP02, no qual se encontrou um solo menos resistente principalmente entre 3 e 6 metros de profundidade, a Tabela 4 mostra em destaque (hachura) que em 5 das etapas de cravação, a eficiência calculada pelo método de Odebrecht (2003) foi consideravelmente maior (diferenças percentuais maiores que 10\%). Consequentemente, para o Ensaio SP02 não é razoável utilizar o a energia teórica como parâmetro, uma vez que dessa forma a eficiência do ensaio será de $25,6 \%$ maior do que pelo método de Odebrecht.

Com os valores de $\mathrm{N}_{\text {SPT }}$ e das energias medidas pelo método EFV para os dois furos de sondagem do estudo, realizou-se uma comparação da energia média necessária para superar uma camada de solo com determinado valor de $\mathrm{N}_{\text {SPT. }}$. A comparação pode ser visualizada na Figura 11. 


\section{TABELA 3: Relação de Energia EPG/E* - Ensaio 01.}

\begin{tabular}{ccccccccccc} 
Prof. (m) & $\mathbf{1 , 0}$ & $\mathbf{2 , 0}$ & $\mathbf{3 , 0}$ & $\mathbf{4 , 0}$ & $\mathbf{5 , 0}$ & $\mathbf{6 , 0}$ & $\mathbf{7 , 0}$ & $\mathbf{8 , 0}$ & $\mathbf{9 , 0}$ & $\mathbf{1 0 , 0}$ \\
\hline EPG/E* & 1,07 & 1,05 & 1,14 & - & 1,04 & 1,03 & 1,05 & 1,07 & 1,05 & 1,05 \\
\hline$N_{\text {SPT }}$ & $\mathbf{6}$ & $\mathbf{1 1}$ & $\mathbf{4}$ & $\mathbf{8}$ & $\mathbf{1 3}$ & $\mathbf{1 8}$ & $\mathbf{1 3}$ & $\mathbf{8}$ & $\mathbf{1 1}$ & $\mathbf{1 3}$ \\
\hline & & & & & & & & & FONTE: Autoria Própria.
\end{tabular}

\section{TABELA 4: Relação de Energia EPG/E* - Ensaio 02.}

\begin{tabular}{ccccccccccc}
\multicolumn{10}{c}{ TABELA 4: Relação de Energia EPG/E* - Ensaio 02. } \\
\hline Prof. $(\mathbf{m})$ & $\mathbf{1 , 0}$ & $\mathbf{2 , 0}$ & $\mathbf{3 , 0}$ & $\mathbf{4 , 0}$ & $\mathbf{5 , 0}$ & $\mathbf{6 , 0}$ & $\mathbf{7 , 0}$ & $\mathbf{8 , 0}$ & $\mathbf{9 , 0}$ & $\mathbf{1 0 , 0}$ \\
\hline EPG/E* & 1,25 & 1,03 & 1,17 & 1,17 & 1,14 & 1,21 & 1,05 & 1,04 & 1,05 & 1,04 \\
\hline $\mathbf{N}_{\text {SPT }}$ & $\mathbf{2}$ & $\mathbf{1 5}$ & $\mathbf{3}$ & $\mathbf{3}$ & $\mathbf{4}$ & $\mathbf{3}$ & $\mathbf{1 3}$ & $\mathbf{1 6}$ & $\mathbf{1 2}$ & $\mathbf{1 3}$ \\
\hline
\end{tabular}

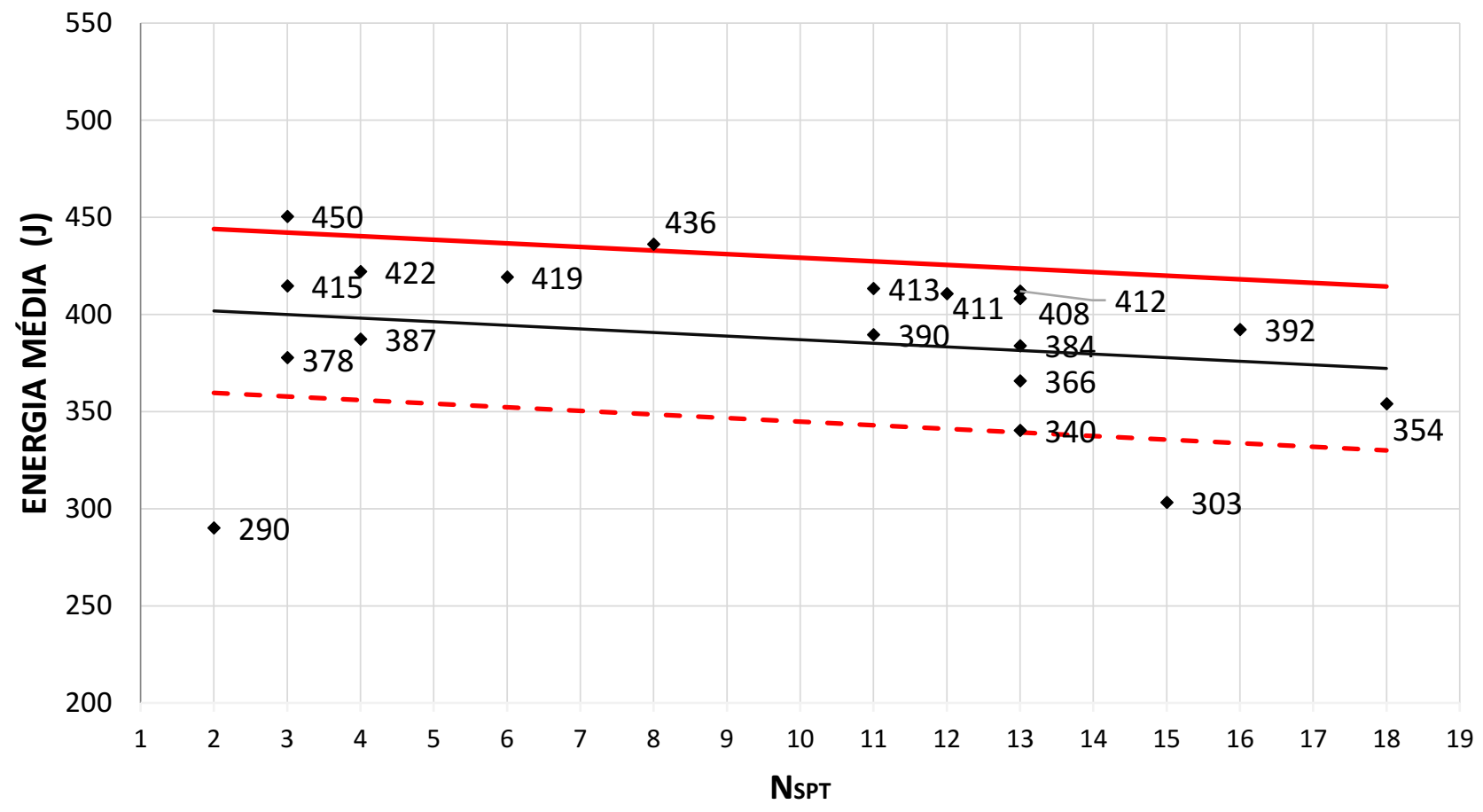

_ Limite Superior _ _ - - Limite Inferior

Linear (SP01 e SP02)

FIGURA 11: Gráfico da energia média pelo valor NSPT.

FONTE: Autoria Própria.

Observando-se a linha de tendência linear, na Figura 11, percebe-se que a energia média medida decresceu levemente com o aumento da resistência do solo à penetração ( $\mathrm{N}_{\mathrm{SPT}}$ ). Além disso, os resultados estiveram, em sua maioria, dentro do limite estabelecido (limite superior e inferior) em função do desvio padrão.

\section{CONCLUSÕES}

Com base nas análises realizadas conclui-se que os resultados de energia utilizando o método EF2 variaram crescentemente com o aumento da resistência do solo e com o comprimento da composição de hastes. Estes resultados de EF2 não devem ser utilizados, porque não representam os reais níveis de energia que são transmitidos à composição de hastes, visto que o método não considera as ondas subsequentes geradas após o primeiro impacto do martelo sobre a "cabeça de bater".

Os resultados obtidos para o método EFV demonstraram a validade da sua utilização, diferentemente do demonstrado pelo método EF2, por considerar a energia que é transmitida às hastes também pelo repique do martelo. 
Os autores do presente trabalho sugerem que, além de se utilizar o método EFV, sempre se utilize o método proposto por Odebrecht (2003) para o cálculo da eficiência de energia do ensaio SPT, pois este método consiste em uma maneira mais completa de se analisar o ensaio. Essa sugestão é embasada no fato de que, apesar da proximidade de 1,95 metros e das semelhantes condições de ensaio dos dois furos de sondagem, constatou-se que, no caso de SP01, seria coerente utilizar a correção para apenas uma etapa de cravação, enquanto que para SP02 seria necessário a correção da eficiência pela energia determinada para $50 \%$ das determinações ao longo do perfil, o que é muito significativo.

A variação encontrada nos resultados de $\mathrm{N}_{\mathrm{SPT}}$, comparando as sondagens SP01 e SP02, demonstrou a influência da presença de fragmentos de pedregulho no furo de sondagem SP01, assim como a necessidade de se ampliar o número de investigações geotécnicas no local, a fim de compreender melhor essas variações na análise espacial do maciço. Dessa forma, a medição de energia pode agregar valor ao ensaio SPT e servir como fator determinante para análise de resultados.

O banco de dados formado pelos resultados da medição de energia realizada neste estudo está disponível para o meio técnico em Jardim; Machado; Jorge (2017) e pode auxiliar em futuras pesquisas externas e no próprio campo experimental da Escola de Engenharia Civil e Ambiental/UFG, em Goiânia.

\section{AGRADECIMENTOS}

À SETE Engenharia, em nome dos engenheiros civis Antônio Luciano Espíndola Fonseca, Valmir Alexandre Merighi e do geólogo Devonzir Magalhães de Oliveira, pelo apoio técnico. À Eletrobras Furnas pelo apoio técnico. À CAPES pela disponibilização do Portal de Periódicos, junto à UFG. A Antônio Belincanta e Juliana Azoia Lukiantchuki pela gentiliza cedendo material bibliográfico. Aos Professores Maurício Sales e Carlos Alberto Vargas pelas valiosas sugestões. À
Giovana Alves de Oliveira pela ajuda na revisão gramatical.

\section{REFERÊNCIAS BIBLIOGRÁFICAS}

ABOU-MATAR, H., GOBLE, G. G. SPT dynamics analysis and measurements. Journal of Geotechnical and Geoenvironmental Enginnering, v. 123, n. 10, 1997, 921 $-928 p$.

AMERICAN SOCIETY FOR TESTING AND MATERIALS (ASTM) D4633-10 - Standard Test Method for Energy Measurement for Dynamic Penetrometers - 2010.

AOKI, N.; ESQUIVEL, E. R.; NEVES, L.F.S.; CINTRA, J. C. A. The impact efficiency obtained from static load test performed on the SPT sampler. Soils and Foundation, 2007. v. 47, n. 6, 1045-1052 p

ASSOCIAÇÃO BRASILEIRA DE NORMAS TÉCNICAS (ABNT), NBR 6484 - Solo - Sondagem de simples reconhecimento com SPT - Método de Ensaio. - Rio de Janeiro, RJ, 2001.

ASSOCIAÇÃO BRASILEIRA DE NORMAS TÉCNICAS (ABNT), NBR 7250 - Solo - Identificação e descrição de amostras de solos obtidas em sondagens de simples reconhecimento dos solos. - Rio de Janeiro, 1982.

BELINCANTA, A. Energia dinâmica no SPT, resultados de uma investigação teórico experimental. Dissertação (Mestrado em Geotecnia) - Escola Politécnica da USP, USP, São Paulo, SP, 1985.

BELINCANTA, A.; ALVIM, F.M.; NAVAJAS, S.; RAMIRES SOBRINHO, R. Métodos para Medida de Energia Dinâmica no SPT. Solos e Rochas, ABMS, 1994, v. 17, n. 2, 93-110 p.

BELINCANTA, A.; FERRAZ, R. L. Fundamentos e métodos de medidas de energia dinâmica no SPT, Acta Scientarium, Universidade Estadual do Maringá, Maringá, PR, 2000, v. 22, n. 5. $1473-1482$ p.

BUTLER, J. J., CALIENDO, J A. \& GOBLE, G.G. Comparison of SPT Energy Measurements Methods. In: Proceedings of the Geotechnical Site Charachterization, Atlanta, EUA, 1998, v.2, $901-905$ p.

CAVALCANTE, E. H., DANZIGER, B. R. e DANZIGER, F. A. B. Measurement of Drop Height and Impact Velocity in the Brazilian SPT System, Soils and Rocks, São Paulo, SP, 2011, N 34, 207-218 p.

CAVALCANTE, E., H. - Investigação Teórico-Experimental sobre o SPT, Tese (Doutorado em Geotecnia) Universidade Federal do Rio de Janeiro, COPPE, Rio de Janeiro, RJ, 2002. 
DÉCOURT, L.; BELINCANTA, A.; QUARESMA FILHO, A.R. (1989). Brazilian experience on SPT. XII International Conference on Soil Mechanics and Geotechnical Engineering. Supplement, Contributions by the Brazilian Society for Soil Mechanics. Rio de Janeiro: ABMS/ISSMGE, 49-54p.

DÉCOURT, L.; MUROMACHI, T.; NIXON, I.K.; SCHMERTMANN, J.H.; THORBURN, S. \& ZOLKOV, E. Standard Penetration Test (SPT): International reference test procedure. In: ISSMFE Technical Committee on Penetration Testing - SPT Working Party, ISOPT I, Orlando, EUA, 1988, v. 1, 3-26 p.

, E. E. Influence of hammer type on SPT results. Journal of Geotechnical Engineering, 1996, v. 122, n. 7, 598-599 p.

FIGUEIREDO, LUIZ CARLOS DE. Medida de energia do DPL com instrumentação dinâmica, Tese (Doutorado em Geotecnia) - Universidade de Brasília, Faculdade de Tecnologia, Brasília, DF, 2016.

GOOGLE MAPS. 2017 Imagem da região da Escola de Engenharia Civil e Ambiental - UFG em Goiânia Referente ao ano de 2017.

HOWIE, J. A., DANIEL, C. R., JACKSON, R.S. and WALKER, $B$. Comparison of energy measurement methods in the standard penetration test. Report prepared for the U.S. Bureau of Reclamation. Geotechnical Research Group, Department of Civil Engineering. The University of British Columbia, Vancouver, Canada, 2003.

KOVACS, W.D. et al. Towards a more standardized SPT In: International Conference On Soil Mechanics and Foundation Engineering, Tokyo, Japan, 1977, v.2, 269$276 \mathrm{p}$.

JARDIM, H. C. O., MACHADO, R. R.., JORGE, P. A. M., Medição de Energia no Ensaio SPT em Solo Tropical do Campo Experimental da Universidade Federal de Goiás, Trabalho de Conclusão de Curso (Graduação em Engenharia Civil), Universidade Federal de Goiás, Escola de Engenharia Civil e Ambiental, Goiânia, GO, 2017.

LUKIANTCHUKI, J. A. Interpretação de resultados do ensaio SPT com base em instrumentação dinâmica. Tese (Doutorado em Geotecnia) - Universidade de São Paulo, Escola de Engenharia de São Carlos, São Carlos, SP, 2012.

LUKIANTCHUKI, J. A., BERNARDES, G.P., ESQUIVEL E.R., Energy Ratio (Eg) for the Standard Penetration Test Based on Measured Field Test . Soils and Rocks, São Paulo, SP, 2017, N 40 (2), 77-91
MORAIS, T. S. O. Interpretação racional de resultados de ensaios SPT com base em conceitos de energia. Dissertação (Mestrado em Geotécnica) - Universidade de São Paulo, Escola de Engenharia de São Carlos, São Carlos, SP, 2014.

MORGANO, C. M., LIANG, R. Energy Transfer in SPT - Rod Length effect. Study prepared for the Application of Stress-Wave Theory of Piles, F.B.J. Barends. Balkema, Rotterdam, Holanda, 1992, 121-127 p.

ODEBRECHT, E. Medidas de energia no ensaio SPT Tese (Doutorado em Engenharia Civil), Universidade Federal do Rio Grande do Sul, Porto Alegre, RS, 2003.

ODEBRECHT, E; SCHNAID, F; ROCHA, M.M; BERNARDES, G.P. Energy efficiency for standard penetration tests. Journal of Geotechnical and Geoenvironmental Engineering, ASCE, 2005, $1252-1263$ p.

PALACIOS, A. The Theory and Measurement of Energy Transfer During Standard Penetration Test Sampling. Dissertation for the Degree of Doctor of Phillosophy (Dissertação de Doutorado). University of Florida, EUA, 1977.

PDI SPT ANALYZER - SPT Users Manual Pile Dinamics Inc., Ohio, EUA, 1995, $30 \mathrm{p}$.

SANTANA, C. M. \& DANZIGER F. A. Monitoramento da Energia em Ensaios SPT Realizados no Estado do Rio de Janeiro. In: Anais do XVIII Congresso Brasileiro de Mecânica dos Solos e Engenharia Geotécnica, Belo Horizonte, MG, 2016.

SANTANA, C. M. SPT Instrumentado em Câmara de Calibração. Tese (Doutorado em Geotecnia), Universidade Federal do Rio de Janeiro, COPPE, Rio de Janeiro, RJ, 2015.

SCHMERTMAN, J.H. \& PALACIOS A. Energy Dynamics of SPT. Journal of the Soil Mechanics and Foundation Division. ASCE. Vol. 105, n. GT8. 1979.

SJOBLOM, D., BISCHOFF, J., AND COX, K. 2002. SPT energy measurements with the PDA. GEOPHYSICS In Proceedings of the 2 nd International Conference on the Application of Geophysicals and NDT Methodologies to Transportation Facilities and Infrastructure, Los Angeles, Calif., 15-19 April 2002, Federal Highway Administration (FHWA), Washington, D.C.

SY, A. \& CAMPANELLA, R.G. An Alternate Method of Measurement SPT Energy In: Proceedings of the 2 International Conference on Recent Advances in Geotechnical Earthquake Engineering and Soil Dynamics, St. Louis, Missouri, EUA, 1991. 499-505 p. 